\title{
学習観がCALL教室における英語学習の成果に及ぼす影響 : クラスター分析を用いた学習者プロファイリング
}

\section{Learner Beliefs in Language Learning in the CALL Environment}

\author{
下山幸成 (しもやまゆきなり) \\ 早稲田大学 \\ 磯田高道（いそだたかみち） \\ 早稻田大学 \\ 山森光陽（やまもりこうよう） \\ 早稲田大学
}

Students' beliefs about language learning and their relationship to learning achievement in a CALL environment were investigated. Unlike previous studies whose purpose was to describe learners' beliefs on each questionnaire item, this study aimed to deal with beliefs comprehensively.

Research on learner beliefs is gaining increasing attention. Behind this trend is the recognition that learners' behaviors cannot be changed unless their preconceptions are changed. Inspired by early studies such as Horwitz (1987), a number of researchers have conducted studies which would supposedly explain the relationship between beliefs and behaviors and, further, provide useful information for learner training. However, most of the studies to date do not take such approaches as to achieve the goals of the beliefs study. The approach of the analysis has been rather descriptive: distribution and frequencies of responses were simply shown. Even though some studies compared the beliefs of different populations, which indicated some significant differences, what we can get from such studies is, again, the description of the populations. To forward the beliefs study, we need to incorporate into the analysis both the beliefs and the behaviors (e.g., motivations, strategies, achievement).

JALT Journal, Vol. 24, No. 2, November, 2002 
This study set out to investigate the intra-relationship between students' beliefs about language learning and their effects on learning achievements. Particular features of this study are; 1) profiling learners by simultaneously analyzing multiple questionnaire items for a comprehensive view of learners, and 2) analyzing the relationship between beliefs and learning achievements. Participants were 77 high school students who were taking EFL courses in a CALL environment. In the class, they mainly worked on a designated CD-ROM material individually. A questionnaire adapted from BALLI (Horwitz, 1987) was used to elicit the participants' beliefs. The items for the questionnaire were chosen by three EFL instructors as related to the learners' CALL experiences. The participants were asked to indicate to what extent they agreed or disagreed to the statement on the questionnaire on a five point scale ranging from 1 (strongly disagree) to 5 (strongly agree).

The analyses had two phases. The first analysis was carried out to profile the learners based on their responses to the questionnaire using cluster analysis (Ward method, squared Euclidean distance technique). This statistical technique is used for finding relatively homogeneous subgroups in the population. This analysis yielded four distinct clusters (numbered cluster 1 to 4), but cluster 4 was not included in the later analysis because it had only two participants in this cluster. The remaining three subgroups are differentially characterized by, in particular, different levels of confidence to learn English and attitudes toward individualized learning. Cluster 1 was a group of students who are less confident about their learning. Cluster 2 showed a high language anxiety and low confidence in learning, but it also showed a favor for individualized learning. Cluster 3 was found active in learning and was differentiated from the other two by the high level of confidence to learn English. Next, the three subgroups were compared on the learning achievements measured by the term-end examinations. One-way ANOVA indicated that there was a statistically significant difference among the three groups' achievements $(\mathrm{p}=.04)$. Post hoc multiple comparison was conducted with Tukey's Method. The results showed that there was a significant difference between cluster 1 and $3(\mathrm{p}=.03)$.

The above results indicate that the CALL environment may have a compensative effect on students whose characteristics are not necessarily advantageous for the traditional classroom learning environment. This implication was drawn particularly from the result for cluster 2 , which is a group of learners whose high anxiety and low confidence to learn English do not seem to favor them. Their characteristics are similar to those of cluster 1 , but the achievements of cluster 2 was not as low as cluster 1 despite their disadvantageous characteristics. This indicates that their CALL experiences, which provide a lot of opportunities for working individually, compensated for their disadvantages which would have inhibited them in a traditional classroom setting. 
本研究では、学習観がCALL教室における英語学習の成果に及ぼす影響を、ク ラスター分析を用いた学習者プロファイリングによって検討した。BALLIの中 から、特にCALL学習に関係が深いものを13項目選び、学習者をカテゴライズ した。その結果、(1)全体的に英語学習に対して消極的な生徒、(2)言語不安が高 く英語学習に対する自信が低いが、対人関係のない個別学習に向く生徒、(3)全 体的に英語学習に対して積極的な生徒、の3つのタイプの学習者に分けられた。

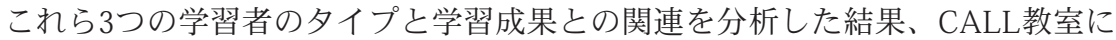
おける英語学習は、従来型の英語の授業では高い学習成果を期待することが難 しい、言語不安が高く英語学習に対する自信が低い、対人関係のない個別学習 に向いている生徒に対して補償的に働くことが示唆された。

丁 Tの進歩に伴い、多くの現場で、テクノロジーを応用した教育が行 われるようになり、機器の利用という観点から多くの研究と実践が なされている。しかし、この動きは、「はじめに機器ありき」の風 潮があり、学習者要因について注意が十分に払われているとは言えない のが現状である。Cognition and Technology Group at Vanderbilt (1996)が 指摘しているように、特にテクノロジーを利用した教育環境のデザイン においては、教育工学、教育問題及び内容、そして学習にまつわる諸理 論の3つを考慮する必要がある。

そこで、本研究では、数多くある学習者要因のうちの一つである学習 観 (learner beliefs : 市川, 1993) が、CALL (Computer-Assisted Language Learning）教室での教育実践の学習成果にどのように影響するのかを検 討する。

外国語教育の実践や研究が学習者中心の方向へ向かうにつれ、学習と いうものの捉え方が、単に知識を受け取る受動的な教育・学習観から、 知識は学習者が構築するものという能動的な教育・学習観に変遷した (Little, 1991; Williams \& Burden, 1997)。その流れの中で、能動的に学習 をコントロールする過程に影響する要因の研究（例えば動機づけ、学習 方略）が盛んになっている。

学習観もその要因のひとつとして研究されているものである。学習観 が研究対象となった理由は、以下のような考えがある。学習者がとる行 動の背景には学習者自身が持つ学習観があり、彼らはそれを基に行動を 選択していると考えられている(Holec, 1987)。そのため、学習者の行動 が望ましくないと判断される時などに教師が介入をする場合があるが、 行動を変えるにはその基にある学習観が変わらなければならないという 観点から、教授学習過程において学習観が重要であると認識されている (Victori \& Lockhart, 1995)。外国語教育以外の分野でも学習観の重要性が 認められ、教育的介入を行って学習観とそれに伴う学習行動を変容させ る試みがなされている（市川, 1993）。 
学習観の影響は様々な場面で見られるが、特に学習者自身がコント ロールできる割合の多い場面で影響が強いと思われる。そのなかで、 CALL教室での授業は普通教室での授業と異なり、個人で行う学習の割 合が多いので、学習観に左右される割合も多いと考えられる。例えば CD-ROM教材を使って学習する場合、行うタスクは皆同じであるが、「 何のために」「言語のどこに注目し」「どのように行うのか」といった 指示が詳細になされている教材はほとんど無く、学習者は自らがそれら を判断しなければならない。このような状況下では、その学習のコント ロールは学習観に影響を受ける可能性が高いと考えられる。仮に同じ教 材を使って学習していたとしても、学習者によっては言語の異なる面に 注目したり、学習の方法も人によって異なることが予想される。

外国語教育研究において学習観の研究が盛んになったのは、1980年代 後半からであるが、その契機となつた研究のひとつがHorwitz (1987)で ある。この研究によって学習観研究が広まった理由は、BALLI (The Beliefs About Language Learning Inventory) が作成された点にある。これ 以降、BALLIが学習観を引き出す道具として数多くの研究で使用されて いる（Horwitz, 1988; Mantle-Bromley, 1995; Kern, 1995）。それらの研究 の報告によると、学習者は全てが同じ学習観を持っているのではなく、 人それぞれに異なっていると言われている。

ただし、それらのBALLIを使った研究（Horwitz, 1988; Mantle-Bromley, 1995; Kern, 1995等）が、学習観研究の本来の目的を達しているとは言い 難い。その理由は2点ある。第1に、研究のアプローチがあくまで記述的な ところでとどまっていることである。分析が被験者全体の傾向を記述統 計（主にパーセンテージ）を用いて表しているにすぎず、学習行動や学 習成果との関連が検討されていない。第2に、質問項目ごとの検討にとど まっており、項目の組み合わせによる学習者のプロファイリングとして 研究がなされていないため、個人の傾向が見えてこないことである。本 来、学習観というものは、学習者一人に対して一つだけ割り当てられて いるものではない。学習者は、学習に対して様々な考えを持っており、 この組み合わせが学習行動や学習成果に対して影響を与えると考えるの が自然である。

BALLIはもともと授業で学習者の学習観を引き出すための道具であっ て、研究のための尺度ではないため、全ての項目が授業過程に関係して いるとは言えない。従って、BALLIを使って学習成果等との関連を調べ る場合、項目の選定が必要であると考えられる。

そこで本研究では、BALLIの項目の中で特にCALLに関係があると考 えられるものを選定し、その上で選定された項目全てへの反応の傾向に 応じて学習者のプロファイリングを行い、学習成果に差があるかどうか 検討した。 


\section{方法 \\ 対象者ならびに授業形態}

対象者は東京都内の私立高等学校の1年生77名で、全て男子である。授 業は1時限50分で、20〜25分を市販のCD-ROMソフトウェアを用いて学習 し、15分程度既成のソフトウェアでタイピングを練習し、残りは、ホー ムページ上で公開されている単語テストや文法テストで学習するという 形式だった。CD-ROMソフトウェアはCALL教室用のもので、リスニン グスキルを伸ばすと同時に語彙・文法の定着を意図した、New Dynamic English (DynEd International, 2000)であった。

\section{質問紙}

BALLI（Horwitz, 1987）の中から、CALL教室での学習と関係が深い と考えられる項目を、東京都内の公立および私立の中学校・高等学校に 勤務する英語教師3名で協議の上、選定した。その結果、表1に示した項 目を利用することを決定した。

\section{表1：本研究で用いたBALLIの項目}

No. 1 私は自分が英語を上手に話せるようになると信じている

No. 2 きれいな発音で英語を話すことが大切である

No. 3 英語を話すためには英語を話す国の文化について知ることが必要だ

No. 4 外国語を学習するのに最大切なことは単語を学習することである

No. 5 何度も繰り返し練習することが大切である

No. 6 日本人は英語を話すのが大切だと感じている

No. 7 他の人と英語で話す際びくびくしてしまう

No. 8 外国語を学習するのに最も大切なことは文法を学習することである

No. 9 カセットテープ等を用いて練習することが大切である

No. 10 英語を学習するのに最大切なことは日本語からの訳し方を学習することで ある

No. 11 英語を上手に学習すればよい仕事につく機会が増える

No. 12 私は英語を上手に話せるようになりたい

No. 13 英語を話したり聞いたりするよりも読んだり書いたりする方が容易である 


\section{学習成果の指標}

New Dynamic Englishに付属のMastery Test（Level 2, Disk 1）を2月に 実施し、その結果を利用した。テスト問題の構成は、リスニングをし ながら文字や絵を選んで解答する選択問題、単語を並べかえて正しい文 を完成させる語句整序問題等であり、全てマウス操作で解答する形式で あった。内容は、2学期後半から3学期の平常授業で練習してきたDaily Activities, Our World, Locationsに関してのものであり、それぞれ100点満 点であった。本研究においては、この3つのテストの合計点を学習成果 の指標として用いた。従って、得点の範囲は0点から300点であった。

\section{結果 \\ 平均及び標準偏差}

まず、本研究で用いたBALLIの各項目の平均及び標準偏差は表2の 通りであった。また、学習成果の平均及び標準偏差は、 $M=229.60$ 、 SD=32.54であった。

表2 本研究で用いたBALLIの各項目の平均および標準偏差

\begin{tabular}{|c|c|c|c|c|c|c|c|c|c|c|c|c|c|}
\hline & $\# 1$ & $\# 2$ & $\# 3$ & $\# 4$ & $\# 5$ & $\# 6$ & $\# 7$ & $\# 8$ & $\# 9$ & $\# 10$ & \#11 & \#12 & $\# 13$ \\
\hline M & 2.95 & 1.74 & 2.84 & 2.58 & 1.38 & 1.88 & 2.77 & 3.09 & 3.14 & 3.34 & 1.60 & 1.55 & 2.74 \\
\hline SD & 1.11 & 0.99 & 1.36 & 1.21 & 0.84 & 0.99 & 1.15 & 1.18 & 1.20 & 1.13 & 0.85 & 0.85 & 1.27 \\
\hline
\end{tabular}

\section{クラスター分析の結果}

SPSSによる、平方ユークリッド距離を用いたウォード法によりクラ スター分析を行い、対象者をいくつかのタイプに分けた。ウォード法を 用いた理由は、この方法によるクラスター分析は、比較的まとまったク ラスターが得られやすく、パターンの分類に有用であると考えられたた めである。この結果得られたクラスターツリーは、Appendixを参照され たい。

実際のグループ分けにおいては、ノンパラメトリック検定の結果を検 討し、最もグループの特徵を記述できるプロフィールの得られる点を探 索した上で、カッティングポイントを定めた。その結果、4つのクラス ターが得られた。各クラスターの所属人数は、第1クラスターが22人、 第2クラスターが35人、第3クラスターが18人であった。しかし、第4ク ラスターについては2名のみの所属であったので、以後の分析に第4クラ スターの生徒についてのデータは利用しない。

次に、クラスター分析の結果の妥当性を検討した。クラスター分析にお いて投入した、13の学習観についての得点が、各クラスター間で差がある 
かどうかを、ノンパラメトリック検定（クラスカルーウォリス検定）の結 果により確認した。通常このような得点の比較には、分散分析が用いられ る。しかし、BALLIの回答などにみられるような順序カテゴリカルデータ に対しては、ノンパラメトリック検定を用いることが推奨されている（石 田、1990）。従って本研究ではノンパラメトリック検定を用いた。一方、 学習成果については一元配置の分散分析を使用した。

その結果、No.1「私は自分が英語を上手に話せるようになると信じ ている」（ $\left.\chi^{2}(2,77)=14.51 、 \mathrm{p}=.001\right) 、 N o .3 「$ 英語を話すためには 英語を話す国の文化について知ることが必要だ」（ $\chi^{2}(2,77)=26.03$ 、 $\mathrm{p}=.000$ ）、No.4「外国語を学習するのに最も大切なことは単語を学習 することである」（ $\chi^{2}(2,77)=17.38 、 \mathrm{p}=.000 ） 、 N o .7 「$ 他の人と英 語で話す際びくびくしてしまう」（ $\left.\chi^{2}(2,77)=7.41 、 \mathrm{p}=.025\right) 、 N o .8$

「外国語を学習するのに最も大切なことは文法を学習することである」

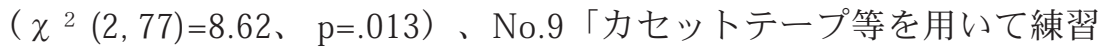
することが大切である」（ $\chi^{2}(2,77)=7.73 、 \mathrm{p}=.021 ） 、 N o .13$ 英語を 話したり聞いたりするよりも読んだり書いたりする方が容易である」

$\left(\chi^{2}(2,77)=26.55 、 \mathrm{p}=.000\right)$ 、以上の7項目について、クラスター間で 有意な差が確認された。また、多重比較の結果および各クラスターの平 均及び標準偏差は表3の通りであった。従って、このクラスター分析の 結果は妥当であると考えられた。

表3: 各クラスターのBALLIの得点の平均, 標準偏差ならびにノンパラメトリック検定の結果

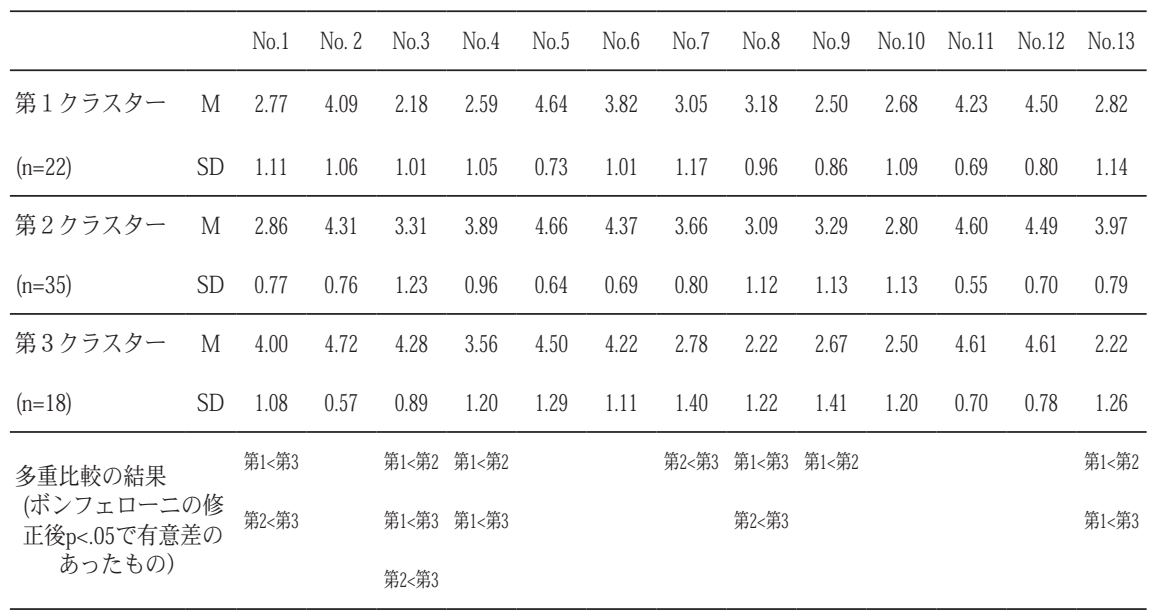




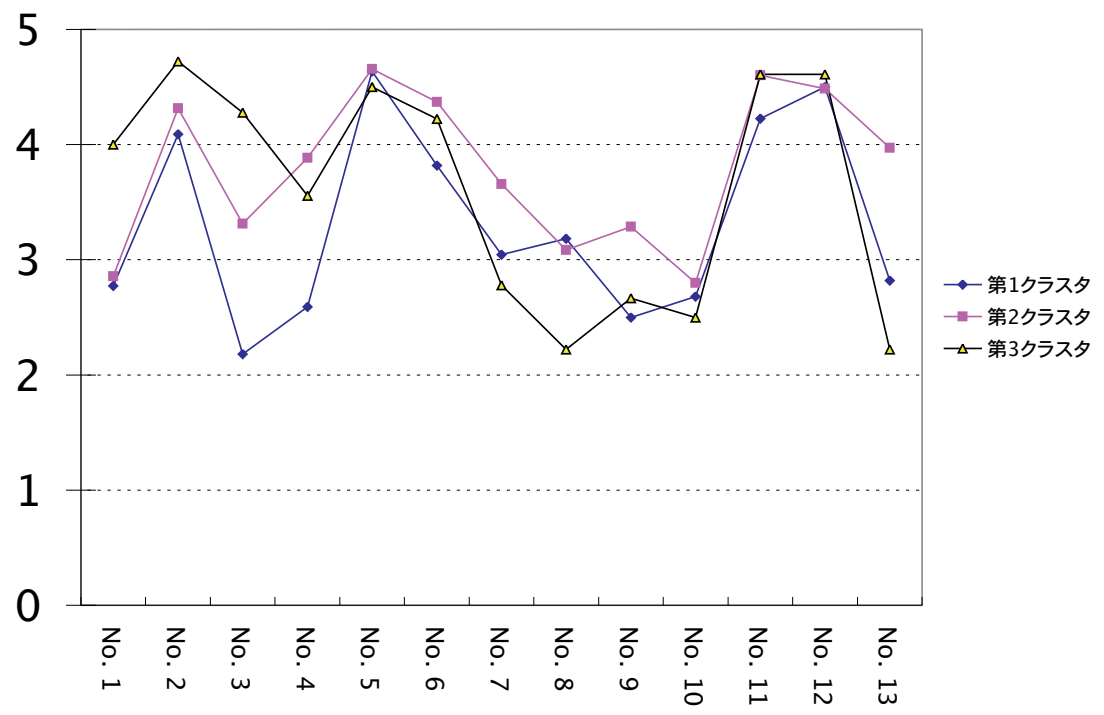

図 1：学習者プロフィール

このクラスター分析の結果、得られた3つのクラスターの特徵をプロ フィールにしたものが図1である。この結果をまとめると、次のように なる。

第1クラスターの生徒は、「自分が英語を上手に話せるようになると 信じている」傾向が強くなく、「英語を話すためには英語を話す国の文 化について知ることが必要だ」とあまり感じず、同時に「外国語を学習 する際単語を学習することが大切だ」とも感じていない。一方で、「文 法を学習することが大切だ」とは普通に感じている。従って、全体的に 英語学習に対して消極的な学習観を有している生徒と言える。

第2クラスターの生徒は、「自分が英語を上手に話せるようになると 信じている」傾向が強くなく、「英語を話したり聞いたりするよりも読 んだり書いたりする方が容易である」と感じていて、「他の人と英語で 話す際びくびくしてしまう」と同時に「カセットテープ等を用いて練習 することが大切だ」と感じている。従って、全体的に消極的で口頭練習 に対する不安が高いが、対人関係のない個別学習に向く生徒と言える。

第3クラスターの生徒は、「自分が英語を上手に話せるようになると 信じている」傾向が高く、「英語を話すためには英語を話す国の文化に ついて知ることが必要だ」と感じている一方で、「外国語学習において 文法を学習することが大切だ」とは感じず、「英語を読んだり書いたり するより話したり聞いたりする方が容易だ」と感じている。従って、全 
体的に英語学習に対して、コミュニケーションを通じて積極的に取り組 む姿勢を持った生徒と言える。

また、学習成果の結果の各クラスター間における差を一元配置の分散

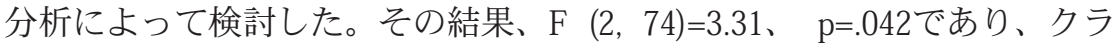
スター間で学習成果に有意差 ( $\mathrm{p}<.05)$ があることが確認された。さらに、 Tukeyの方法を用いた多重比較を行った結果、第1クラスターと第3クラス ターとの間で、学習成果に有意差 $(\mathrm{p}=.03)$ があることが確認された。つま り、第1クラスターの生徒は、第3クラスターの生徒に比べて、学習成果 が有意に低いことが示唆された。

表4： 各クラスターの学習成果についての平均と標準偏差

\begin{tabular}{lccc}
\hline & 第1 クラスター & 第2 クラスター & 第3 クラスター \\
\hline $\mathrm{M}$ & 219.55 & 230.23 & 244.89 \\
$\mathrm{SD}$ & 30.83 & 31.88 & 29.44 \\
\hline
\end{tabular}

\section{考察}

本研究が、学習観と外国語学習との関係を扱った他の研究と一線を画 すのは、次の2点である。第1は、従来の研究に見られるように、学習観 の善し悪しを論じるのではなく、項目の組み合わせによる学習者のプロ ファイリングを行い、包括的な学習者像を捉えようとした点である。第 2は、学習者のタイプの違いと学習成果との関係を論じた点である。

本研究の結果得られたクラスターのうち、最も学習成果が高かった群 は、第3クラスターに属する生徒であった。このクラスターに属する生徒 は、英語学習に対する自信が高く、コミュニケーションを通じて積極的 に英語学習に取り組む姿勢を持った、外国語学習に対して促進的に働く と考えられる学習観を有している生徒であると言えよう。このような生 徒の場合、CALL教室においての英語学習のみならず、普通教室における 従来型の英語学習においても、同様に良い学習成果を修める生徒である と考えられる。従って、このような語学学習に対して促進的に働くと考 えられる学習観を持ち合わせていることが、CALL教室における学習に対 してのみ促進的な効果をもたらすというわけではないと言えよう。

一方、最も学習成果が低かった群は第1クラスターに属する生徒であ つた。このクラスターに属する生徒は、英語学習に対する自信が低く、 全体的に英語学習に対して消極的な学習観を有していると考えられる生 徒であった。このような生徒は、CALL教室での学習に限らず、英語学 習全般においても、高い学習成果を期待することは難しいと言えよう。

ここで最も問題としたいのは、第2クラスターに属する生徒である。 
このクラスターに属する生徒は、第1クラスターの生徒と同様に英語学 習に対する自信が低く、さらに「他の人と英語で話す際びくびくしてし まう」という項目の点が高いことから、言語学習不安が高い生徒である と言える。しかし本研究において、第2クラスターの生徒の学習成果は 統計的有意差は認められなかったものの、素点を検討した結果、第1ク ラスターの生徒ほど低くはなかった。

Horwitz (1986), Young (1986), MacIntyre and Gardner (1994)など、多くの研 究において、言語学習不安と学習成果との間には有意な負の相関がある という結果が得られている。さらに、Salili, Chiu and Lai (2001) が指摘して いるように、英語学習に対する自信と学習成果との間には、有意な正の 相関があると考えられてきた。従って、英語学習に対する自信が低いこ ともまた、低い学習成果につながると考えられる。これらの先行研究に 従って考えると、第2クラスターの生徒の学習成果が第1クラスターの生 徒と同様に低くなると予測できる。しかし実際は、第2クラスターの生徒 の学習成果は、第1クラスターの生徒ほど、低くはなかった。

第2クラスターの生徒も、第1クラスターの生徒と同様に一般的には高 い学習成果を期待することは出来ないように考えられる。だが、このク ラスターの生徒は、No. 9「カセットテープ等を用いて練習することが大 切である」において第1クラスターの生徒との間に有意差が認められた ことから、対人関係のない個別学習を好む生徒であったと考えられる。 CALL教室における学習は、従来型の教室で行われる英語の授業とは異 なり、周りの生徒や教師のことを意識することなく、個人のペースで学 習を進められることが特徵である。従って、対人関係のない個別学習を 好む学習観を持っていることが促進的に働いた結果、言語学習不安が軽 減され、第1クラスターの生徒のような低い学習成果にはつながらなか つたと考えられる。

以上の点から、CALL教室における学習は、従来型の英語の授業では 高い学習成果を期待することが難しいが、個人で学習を進めることに対 しては肯定的な学習観を持つ生徒に対して、補償的に働く可能性のある ことが示唆された。

このことは、必ずしもCALL教室での授業が他の形態の授業に比べて 望ましいという結果にはつながらない。山森・前田・磯田 (2002)が指摘 しているように、適性処遇交互作用のパラダイムを援用すると、一つの 授業形態に向く生徒がいるということは、それ以外の形態での授業に向 く生徒が存在する可能性をも示唆していると言えよう。CALL教室での 授業に向く生徒がいると言うことが確認されたことは、一方で、従来型 もしくはそれ以外の形態での授業に対して向く生徒が存在する可能性も 否定できないのである。Sternberg (1996) は、一つの教室に存在する多様 な個性に対応するためには、一つのクラスにおいて、様々な教授法を切 り替えて授業を行う必要があることを、認知心理学の研究成果をもとに 
指摘している。またSawyer and Ranta (2001) は、多様な個性の持ち主であ る学習者に対してどのような学習法が有効であるかの検討を個人差研究 は可能にするとし、言語教育学の新地平を切り開く可能性があると指摘 している。つまり、CALL教室での授業も含めた多様な形態での学習機 会を提供することが、我々英語教師に課せられていると言えよう。

\section{結論}

本研究では、学習観とCALL教室における英語学習の成果との関係を、ク ラスター分析を用いた学習者プロファイリングによって検討した。BALLIの 中から、特にCALL学習に関係が深いと考えられるものを13項目選定し、学 習者をカテゴライズした。その結果、(1)全体的に英語学習に対して消極 的な生徒、(2)言語学習不安が高く英語学習に対する自信が低いが、対 人関係のない個別学習に向く生徒、(3)全体的に英語学習に対して積極的

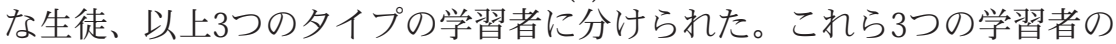
タイプと学習成果との関連を検討した結果、言語学習不安が高く、英語 学習に対する自信が低く、かつ対人関係のない個別学習に向くという、 従来型の英語の授業では高い学習成果を期待することが難しい生徒に対 して、CALL教室における英語学習は補償的に働くことが示唆された。

この結果を解釈する上で注意すべき点は、CALL教室での授業が従来 型の授業に比べて優れているという結果にはならない点である。適性 処遇交互作用のパラダイムに基づいて考えると、CALL教室での授業を 好む生徒が存在するということは、それ以外の形態での授業を好む生徒 が同時に存在する可能性があるということである。従って、教師は、生 徒の多様性に応じて多様な学習環境を提供する必要性を忘れてはならな い。

最後に、CALL教室における授業以外の多様な授業形態に対しても、 本研究と同様の方法によって検討を行うことにより、学習者の特性を考 慮した教育環境のデザインを可能とすると考えられる。

\section{執筆者略歴}

下山幸成 (SHIMOYAMA, Yukinari) 早稲田大学大学院教育学研究科博士 課程在籍。早稲田実業学校英語科講師。専門は応用言語学，教育工学。 特にLL・CALLを用いた教育実践及びシラバスデザイン。

磯田貴道 (ISODA, Takamichi) 早稲田大学大学院教育学研究科博士課程 在籍。早稲田実業学校英語科講師。専門は応用言語学。特に外国語学習 における学習者要因および認知心理学的要因について。

山森光陽（YAMAMORI, Koyo）早稲田大学大学院教育学研究科博士 課程在籍。世田谷区立駒留中学校英語科講師。専門は教育心理学。特に 適性処遇交互作用（ATI），学習意欲，教育評価および測定。 


\section{参考文献}

Cognition and Technology Group at Vanderbilt. (1996). Looking at technology in context: A framework for understanding technology and education research. In D. C. Berliner \& R. C. Calfee (Eds.), Handbook of educational psychology (pp. 807-840). New York: Simon \& Schuster Macmillan.

DynEd International. (2000). New Dynamic English (Version 3.0) [Computer software]. Burlingame, CA: DynEd International.

Holec, H. (1987). The learner as manager; managing learning or managing to learn? In A. Wenden \& J. Rubin (Eds.), Learner strategies in language learning (pp. 145-157). London: Prentice Hall.

Horwitz, E. K. (1986). Preliminary evidence for the reliability and validity of a foreign language anxiety scale. TESOL Quarterly, 20, 559-562.

Horwitz, E.K. (1987). Surveying students' beliefs about language learning. In A. Wenden \& J. Rubin (Eds.), Learner strategies in language learning (pp. 119 -129). London: Prentice Hall.

Horwitz, E.K. (1988). The beliefs about language learning of beginning university foreign language students. The Modern Language Journal, 72, 283-294.

市川伸一 (1993) 『学習を支える認知カウンセリング二心理学と教育の新たな接 点』ブレーン出版

石田潤 (1990)「データを数值で表現する方法」森敏昭・吉田寿夫（編）『心理 学のためのデータ解析テクニカルブック』北大路書房

Kern, R. (1995). Students' and teachers' beliefs about language learning. Foreign Language Annals, 28, 71-92.

Little, D. (1991). Learner autonomy 1: Definitions, issues and problems. Dublin: Authentik Language Learning Resources Ltd.

MacIntyre, P. D. \& Gardner, R. C. (1994). The effects of induced anxiety on cognitive processing in second language learning. Studies in Second Language Acquisition, 16, 1-17.

Mantle-Bromley, C. (1995). Positive attitudes and realistic beliefs: links to proficiency. The Modern Language Journal, 79, 372-386.

Salili, F., Chiu, C. \& Lai, S. (2001). The influence of culture and context on students' motivational orientation and performance. In F. Salili, C. Chiu, \& Y. Hong (Eds.), Student motivation: The culture and context of learning (pp. 221-247). New York: Kluwer Academic/Plenum Publishers.

Sawyer, M \& Ranta, L. (2001). Aptitude, individual differences, and instructional design. In P. Robinson (Ed.), Cognition and second language instruction (pp. 319-353). Cambridge: Cambridge University Press.

Sternberg, R. J. (1996). Matching abilities, instruction and assessment: reawakening the sleeping giant of ATI. In I. Dennis \& P. Tapsfield (Eds.), Human abilities: Their nature and measurement (pp. 167-181). Mahwah: Lawrence Erlbaum Associates.

Victori, M. \& Lockhart, W. (1995). Enhancing metacognition in self-directed language learning. System, 23, 223-234.

Williams, M. \& Burden, R. (1997). Psychology for language teachers. Cambridge: Cambridge University Press.

山森光陽・前田啓朗・磯田貴道 (2002)「個人差を考慮した教育環境のデザイン : 学習者の特性と教育環境との交互作用」『外国語教育メディア学会第42回 全国研究大会発表要項』156-157

Young, D. (1986). The relationship between anxiety and foreign language oral proficiency ratings. Foreign language Annals, 19, 439-445. 